Please send trade news information and

illustrations to Arveen Bajaj at the BDJ, Nature

Publishing Group, The Macmillan Building,

4-6 Crinan Street, London N1 9XW.

Trade news is provided as a service to readers

using text and images from the manufacturer,

supplier or distributor and does not imply

endorsement by the BDJ. Normal and prudent

research should be exercised before purchase or

use of any product mentioned.

\section{Digital imaging solutions}

Imaging Technologies, specialists in imaging and X-ray offer a number of solutions to the dental practice wishing to fully or partially digitise their X-ray and imaging systems.

Working in conjunction with leading manufacturers, Imaging Technologies and its experienced personnel offer a completely unbiased service to the dental profession.
It brings many of the products available in the market place to your door - for hands on demonstration and trial.

The product range available offers a full clinical solution including OPG, ceph, intra-oral sensors and cameras as well as specialist CT/conebeam technology.

Imaging Technologies are agents for Durr, VistaScan and VistaCam intra-oral camera, the Owandy Krystal $\mathrm{X}$ range and are newly appointed agents for the Integradent/VATECH product range.

Reader response number 50

Peelvue Sterilisation Pouches are available in a wide range of sizes to fit many tools, including burs, hand instruments, surgical, orthodontic and multiple instruments.

Reader response number 51

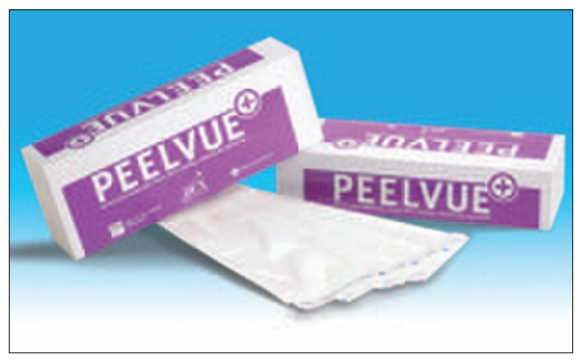
wearing gloves.

\section{Faster crown removal}

Coltène Whaledent presents Diatech Speedster carbide burs specifically designed for the rapid reduction of amalgam, gold, porcelain, PFM and enamel. The computer designed bur flutes are cut in concentric one-piece solid carbide, to

eliminate vibration and give a longer cutting life.

With higher cutting efficiency, crown removal is two to three times faster than equivalent diamond and other carbide burs and the exclusive end cut design can be used for endo access.

Reader response number 52

\section{Extra protection for patients' teeth}

The new Tooth Mousse stand carries a quantity of patient leaflets that give simple details as to the benefits of Tooth Mousse. By placing the stand in the reception area your patients could be given a leaflet by your receptionist to browse through whilst waiting for their appointment.

GC Tooth Mousse is a water-based, sugar-free topical cream that contains Recaldent CPP-ACP (casein phosphopeptide - amorphous calcium phosphate). This topical paste provides extra protection for the patients' teeth.

Tooth Mousse is used to provide protection for teeth and to help neutralise an acidic oral environment. Additional professional applications of the mousse include immediately following bleaching, after ultrasonic, hand scaling or root planing, after removal of orthodontic brackets, following professional tooth cleaning, after application of topical fluoride and also to provide a topical coating for patients suffering from erosion, caries and conditions arising from xerostomia.

GC is giving away the Tooth Mousse stand free with every ten-pack of Tooth Mousse ordered. It is available in the flavours Strawberry, Melon, Vanilla, Mint and Tutti Frutti.

\title{
Straight picture of jaw surgery
}

A new DVD has been launched by a group of orthodontic consultants in collaboration with the British Orthodontic Society. 'A Patient Guide to Orthognathic Surgery' incorporates interviews with patients as well as animations to explain the treatment.
The content has been broken down into sections so patients can easily view the part which applies to them at the most relevant time.

For more information, email ann. wright@bos.org.uk.

Reader response number 53
Reader response number 54

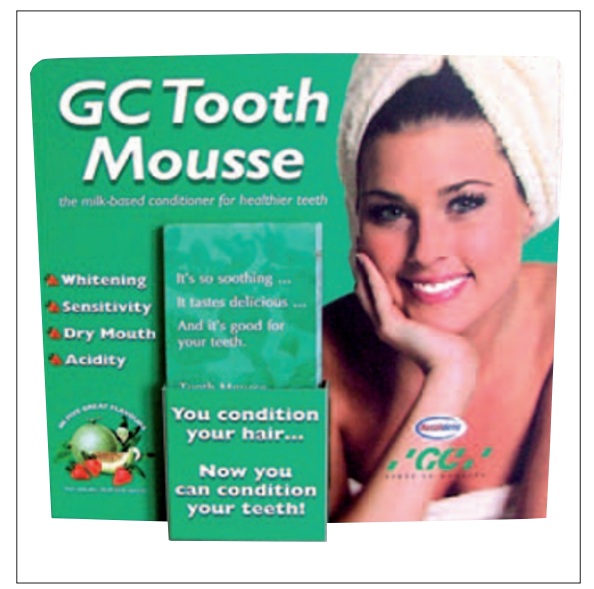



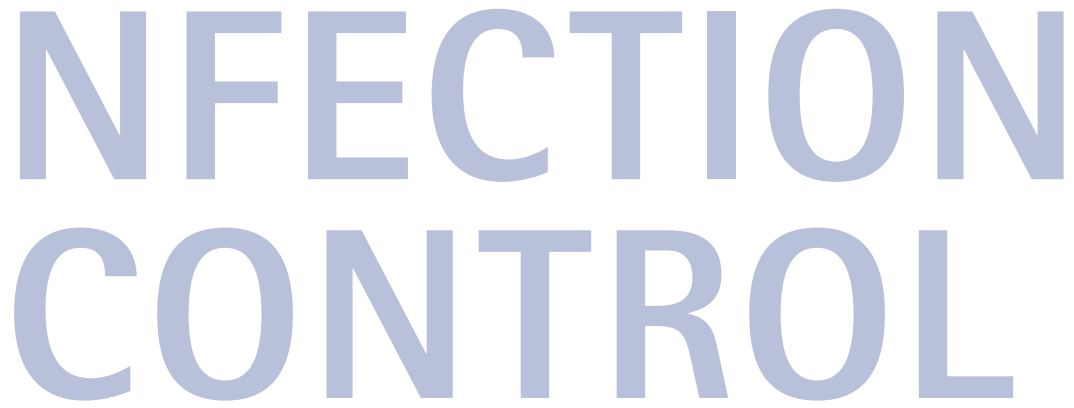

\section{Cleaning to the cellular level}

Sultan Healthcare has recently launched Solo Disinfectant Cleaner, the all-inone, alcohol free disinfectant that deep cleans to the cellular level removing biofilm and deactivating bacteria, viruses and fungi.

The cleaner comes in economical and space saving dispensing bottles and is effective against TB, drug resistant bacteria such as MRSA and GRSA and viruses such as HIV and Avian influenza.

Solo deactivates micro-organisms at the cellular level by penetrating the cell wall and attacking the cell contents. Its powerful cleaners then lift soils to effectively remove biofilm from the surface and provide maximum cleaning and disinfection.

The product is safe to use on medical devices and equipment because there are no harmful chemicals such as alcohols or aldehydes. It cleans and disinfects opera-

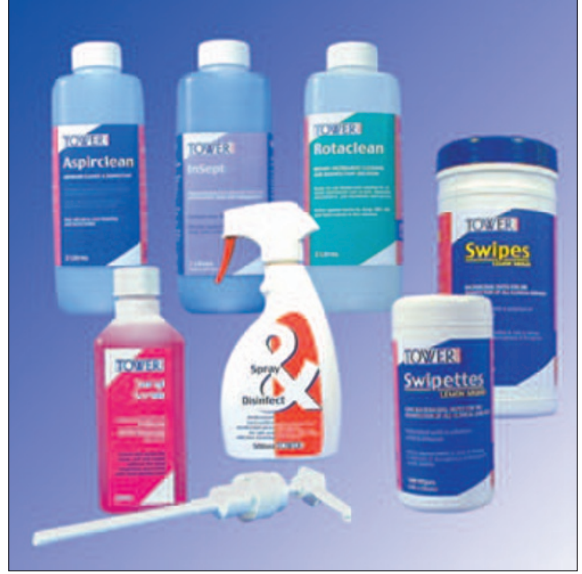

tory chairs, instruments, impressions, medical devices, equipment and other hard surfaces leaving a fresh clean scent.

Solo is available in concentrate and ready-to-use formats depending on the needs of each surgery. The concentrates provide a low cost space saving solution and are easy to use, while the ready-touse products are simple and effective. Reader response number $\mathbf{5 5}$

\section{Anti-bacterial glass launched}

AGC Flat Glass Europe, formerly Glaverbel, has introduced its new AntiBacterial Glass to the market. AntiBacterial Glass kills $99.9 \%$ of bacteria and stops the spread of fungi in the fight against hospital caught infections. The glass eliminates micro-organisms as soon as they come into contact with its surface. The glass's antibacterial action is based on silver which involves diffusing silver ions into the upper layers of the glass: the ions interact with bacteria and destroy them by disabling their metabolism and disrupting their division mechanism. The glass can be used for all kinds of surfaces, from glazing to wall coverings and mirrors.

Reader response number 56

\section{Alcohol-free solutions}

The new GreenctClean SK disinfection and cleaning foam and the ready-to-use disinfection and cleaning wipes from Metasys are suitable for disinfecting delicate surfaces such as upholstery on chairs and stools, acrylic and plexiglass.

Besides an effective disinfection result, the product should clean without damaging or cracking the surface. Furthermore, a short action time is essential as there is often not much time between dental treatments.

The scented foam cleans and disinfects without irritating the mucous membranes. It can be used directly on the surfaces as can the handy, ready-to-use wipes. It is biodegradable, pH-neutral and covers a broad disinfectant spectrum (HBV/HIV/HCV, bactericidal, fungicidal) with a 60 second action time.

Reader response number 57

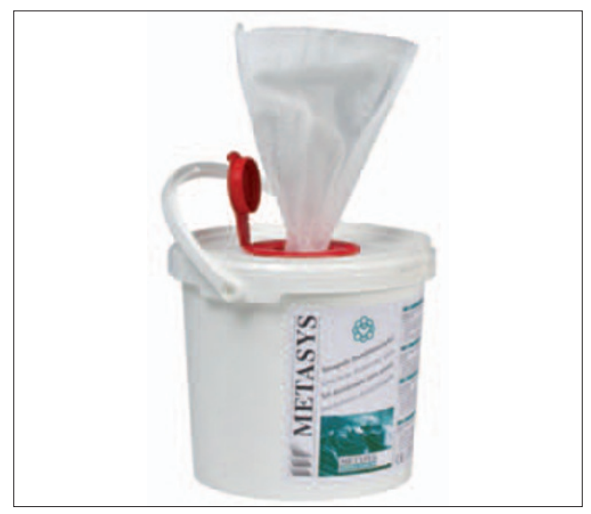

\section{Healthy hands}

The Gojo skin care regimen, from Trycare Dental Linkline consists of Antibacterial Lotion Soap, Gojo Antibac Lotion Soap and Purell Instant Hand Sanitizer. Gojo Antibacterial Lotion Soap kills microorganisms, but is gentle on hands even after repeated daily washing. It contains Chloroxylenol quick-acting antimicrobial

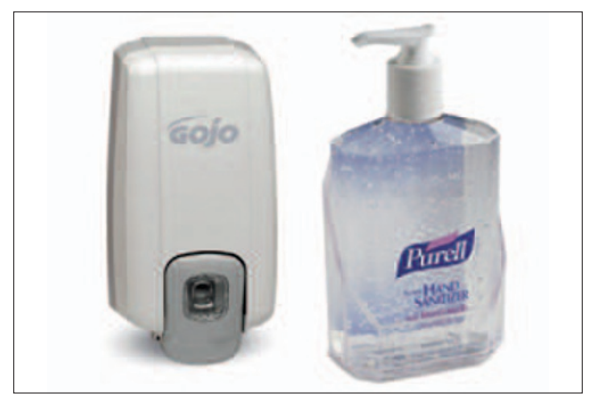

agent and kills 99.5\% of most common bacteria in 30 seconds. Fragrance free, it has a non-drying formula containing moisturisers to facilitate frequent use.

Purell Instant Hand Sanitizer kills $99.99 \%$ of most common micro-organisms and is convenient to use anytime. It simply evaporates quickly to leave hands feeling soft and refreshed.

Reader response number 58 


\section{Sterile endodontic instruments}

Quality Endodontic Distributors Ltd have introduced triniti ${ }^{\circledR}$ Nickel Titanium Instruments and SteriFiles ${ }^{\circledR}$. Both are supplied sterile and individually blister packed.

triniti ${ }^{\circledR}$ Nickel Titanium Instruments were developed to meet the demands of GDPs who want the benefits of rotary

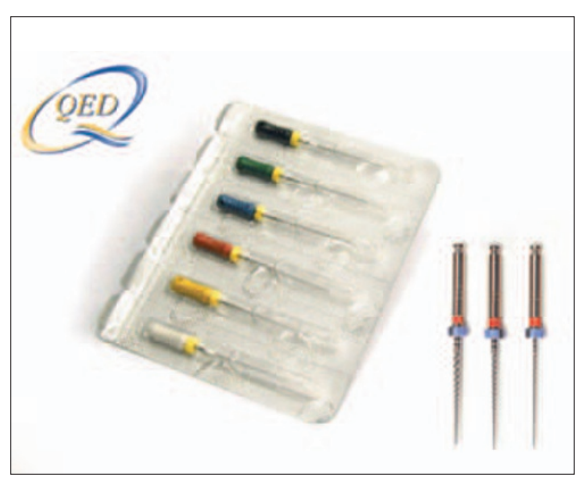

\section{Dry air guaranteed}

Seal-Tight 3 in 1 disposable syringe tips from Kerr have a separate air and water supply through the Seal-Tight tip assuring complete peace of mind due to the 0 -ring being built into the tip. Dry air is guaranteed every time resulting in fewer restorative failures owing to moisture contamination during the bonding process.

\section{Machines do the hard work}

Manufacturer of instrument decontamination equipment, Eschmann provide a choice of benchtop and underbench, state-of-the-art washer disinfectors. The new benchtop Little Sister IWD 51htm eliminates the risks associated with pre-sterilisation cleaning methods, and leaves the hard work to two built-in high pressure sprays that work effectively to remove organic debris throughout each of its three cycles.

Warm air is circulated by employing active systems to ensure that instruments are thoroughly dried, reducing the risk of tarnishing. Rapid instrument cleaning can be completed in less than 20 minutes. Disinfection can be enabled, ensuring safer handling of instruments prior to sterilisation.

The Little Sister IWD7881 underbench will also ensure that your dental practice meets requirements for pre-sterilisation cleaning with benefits including capacity to meet instrument cleaning requirements in large quantities. instrumentation, within NHS constraints.

They have an innovative cross section which allows more free space for debris removal. Whilst retaining its core strength, it also allows excellent flexibility and maintains a perfect cutting edge. The non-cutting tip reduces the risk of perforations. They enable clinicians to prepare root canals in a simple crown down technique requiring fewer instruments.

SteriFiles ${ }^{\circledR}$ are designed for conventional endodontic instrumentation. Supplied in $\mathrm{K}$ and $\mathrm{H}$ Type presentations they are manufactured from high-grade stainless steel, which maximises both flexibility and strength. The K Type file features an enhanced non-cutting tip, for preparing curved and narrow canals. Reader response number 59

Many of the disposable 3 in 1 syringe tips on the market cannot guarantee dry air as the 0-ring is not an integral part of the tip, resulting in moisture being incorporated in the air supply. SealTight offers easy and fast push-in and pull-out tip release, saving time. The tip can be bent to a convenient angle ensuring you have access to all areas of the oral environment.

Reader response number 60

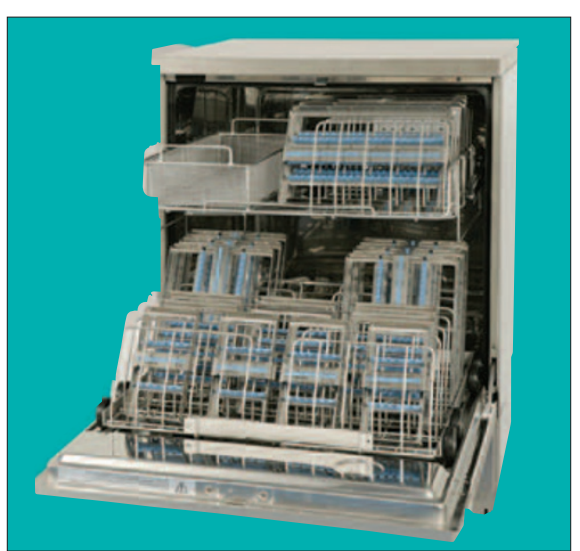

The IWD 7881 is available in a range of models to suit all needs and comes in high-grade stainless steel and white enamel casings. Features include a 40 minute wash and disinfection cycle, handpiece irrigation, cycle and temperature fault indicators, water and electricity saving features.

Fully compatible with the new Eschmann instrument Management System (EiMS) including HFiT cassettes, the units help to minimise sharps injury and prevent damage to delicate instruments. Reader response number 61 